\title{
Young people's perceptions of and experiences with drugs: findings from an Irish study
}

\author{
Abbey Hyde, Margaret Treacy, Teresa Whitaker, Pilar Santos Abaunza, Barbara Knox
}

\begin{abstract}
This paper presents data from Irish children on their perceptions and experiences in relation to illicit drugs as they approached adolescence. Depth interviews were conducted with.78 participants and data were analysed using a qualitative strategy whereby data were categorized into conceptual themes. Findings suggested that most participants had a high level of exposure to a drug culture, yet had little direct experiences with actually being offered or using drugs. A small minority had used cannabis and tended to frame the substance and its use in benign terms. Most children, however, expressed anti-drug attitudes. Participants' knowledge of the outcome of drug use tended to be vague or dramatic.
\end{abstract}

Keywords: drugs, children, perceptions, Ireland

\section{INTRODUCTION}

Research suggests that while unusual in early adolescence, illegal drug use escalates during the middle teenage years and peaks in the late teens ${ }^{1}$. A Mid-West Irish study found a lifetime prevalence for cannabis use to be 5.3 per cent at 13 years rising to 33.1 per cent by the age of $17^{2}$. Indirect indicators suggest that the problem of drug abuse, particularly 'hard' drug abuse, has been an escalating one in the Republic of Ireland over the past 20 years ${ }^{3,4}$. The small number of studies conducted on young people and illegal drug use in Ireland gives some indication of the scale of the problem among adolescents. As part of European research, a national survey found that among 16-year-olds, 37 per cent had used cannabis, 16 per cent had used an illegal substance other then cannabis, and 7 per cent had used tranquillisers

Abbey Hyde, Lecturer, Margaret Treacy, Head of School, School of Nursing and Midwifery, Teresa Whitaker, University Tutor (and doctoral student). Department of Sociology, University College Dublin, National University of Ireland, Dublin 2, Republic of Ireland. Pilar Santos Abaunza, Lecturer in Nursing, University of Cantabria, Spain. Barbara Knox, Research Fellow, NICHE, School of Bio-medical Sciences, University of Ulster, Northern Ireland. Correspondence to Dr A Hyde. 
or sedatives without a prescription ${ }^{5}$. More recent research on people between the ages of 15 and 24 found that 53 per cent reported having taken illegal drugs, 12 per cent reported currently taking them once or twice per week, 22 per cent taking them once or twice per month and 34 per cent using drugs three to four times a year ${ }^{6}$.

A dominant theme emerging in UK literature on the extent of illegal drug use among young people was that the practice had become so widespread that it was the norm for adolescents in Britain $^{7-9}$. It appears that this view is shared by those working directly with young people in Ireland $^{6}$. However, this 'normalisation' thesis has been refuted by Shiner and Newburn ${ }^{10}$ who criticise survey methods used in drug behaviour research for their use of lifetime measures (that is, asking participants whether they had ever used drugs). When shorter time-frames were used within these surveys, the degree of drug use reported decreased considerably. Furthermore, Shiner and Newburn ${ }^{10}$ furnished their own qualitative data indicating that, irrespective of whether they had used drugs or not, young people in their study (of mostly 14-15-year-olds, but with nearly a quarter aged 11-14), actually held fairly conservative views on illegal drug use, akin to those of adults. This, they argued, demonstrated that illicit drug use was not widely perceived to be an acceptable practice by young people, although they do warn against complacency on the drug issue. In addition, supporting earlier research ${ }^{11}$, they noted that drug takers used 'neutralisation techniques, ${ }^{12}$, or mechanisms that permit drug use without feelings of guilt. These techniques include individuals explaining their drug use in terms of peer influence or framing some substances as not really 'drugs' 10 .

In this article, the data set presented on children's perceptions of and experience with drugs is part of a wider study on children's health and lifestyles with a particular focus on the initiation of cigarette smoking. Although smoking is the central practice of concern of the study overall, an understanding of children's lifestyles more generally was deemed essential to comprehend the complex reasons that lead children to smoke. As the wider study progresses, it is anticipated that data on the children's perceptions of and experiences with drugs (and indeed other aspects of their lifestyles) will be used to enrich an understanding of why children do or do not become smokers. The subject matter of this paper is confined to the issue of drugs, and is a useful knowledge base in itself.

\section{METHODS}

Research presented in this paper is part of a large comparative and longitudinal study. The wider study is comparative insofar as three countries are involved - the Republic of Ireland, Northern Ireland, and Spain - and ultimately a comparison will be made between findings from each nation. It is longitudinal in that the sample from each country is followed through for three years from first contact. Data presented in this paper are confined to a cross-section of the first year of data collection, from one of the centres, the Republic of Ireland. The comparative and evolving aspects of the project over time will be published in due course.

The following account on methodology details the strategy utilised by the Republic of Ireland research team. A sample of 78 (44 girls and 34 boys) with an average age of 11.5 years was selected from 11 different youth clubs. These clubs were 
drawn from an unrestricted and comprehensive list of over 100 possible youth clubs, compiled with the help of numerous youth organisations throughout the Republic of Ireland. The 11 clubs chosen (approximately 10 per cent of the overall youth-club sampling frame) were selected on the basis of the youth club leaders willingness to support the research, and the accessibility of the club location. The children's initial source of information about the study was through their youth club leader. The research team believed that an approach by the leaders would bring credibility to the research and increase the uptake by participants. Since the initial invitation to participate in the study came from the club leader, the proportion of children who refused to participate is not known.

While most children in the sample were selected from mainly working-class areas of Dublin $(n=71)$, a smaller number $(n=7)$ was selected from Galway City and Bray (an urban centre in Wicklow, extending from Dublin). After having obtained consent from the child's parent, each participant was interviewed at a youth club. An interview guide was used by the interviewer, which covered topics such as cigarette smoking, drugs, alcohol, recreational activities, and health perceptions. In keeping with the spirit of depth interviewing, the children were encouraged to develop their own narratives on these topics. However, methodologists have identified difficulties associated with adults interviewing children ${ }^{13}$, in particular the reluctance of some children to open up in an interview situation, and this was noted in the present study and is the subject of another paper (in preparation). Nonetheless, the considerable sample size for a study of this kind ensured that a considerable quantity of data was yielded. Data analysis was facilitated by using the software package NUD*IST. Like items of data were grouped and regrouped, and themes were developed from these.

\section{FINDINGS}

Data about drugs were categorised into the following four themes: the children's knowledge of drug names; their awareness of drug-use in their social environment; participants' direct experiences with drugs; and knowledge and understanding of the effects of drugs.

\section{The children's knowledge of drug names}

No definition of the word 'drug' was imposed on the children; rather, their own construction of what could be labelled a drug was sought. While some children could not (or in one case at least, would not) name a drug, the majority of children could name at least two drugs. Almost all referred to illegal substances. The most frequently named drug was heroin (occasionally referred to as 'smack'), followed by cannabis (also called marijuana, 'hash', 'dope' or 'pot') and cocaine (also called 'coke' or 'crack'). Other drug names known were ecstasy and speed.

\section{Children's awareness of drug-use in their social environment}

There was strong evidence in the data that many participants were exposed to a drugs subculture in their everyday lives through a number of means. These included: seeing evidence left behind by users in the form of drug debris; actually 
witnessing drug dealing; having an awareness of specific social locations in the area where drugs were exchanged or used; and seeing anti-drug slogans and marches in their neighbourhood.

Evidence of drug-use in their area was most commonly found in the form of material remains left by drug-takers.

Well we seen syringes on the road: They were in a bag and we just walked away from them, we didn't touch them.

(No. 55, girl, 11 years)

A smaller number of children reported actually observing drugs being used and/or exchanged.

Interviewer: Do you know anyone taking drugs?

I don't know names but I always see boys doing it around the swings where me sisters go to playschool and all. They do be hanging around there on a Wednesday at around 5pm.

Interviewer: How do you know they are taking drugs?

Cos I do be seeing them hanging around and dealing and stuff.

(No. 30, girl, 11 years)

Interviewer: Have you seen any drugs in [names area] when you were here?

Seen drugs? Yeah they are always dealing drugs in the back of the shops.

Interviewer: Dealing?

Yeah.

Interviewer: How do you know they are dealing behind the shops?

Because they are giving them bags of money and bags like bags of sugar you know the way it looks like. I know where they hide it as well, you know the post office and all, they put it up when the shutters be put down and then collect it in the morning.

(No. 51, girl, 12 years)

In addition to seeing waste products left by drug users or actually witnessing drug dealing or consumption, a number of children referred to social locations which were renowned locally as sites of drug use.

Interviewer: Do you know anyone in your area that takes drugs?

Down in the snooker hall, and some of them do be off their heads.

(No. 35, girl, 11 years)

A few children revealed that their consciousness of drug-use in the neighbourhood came from seeing anti-drug slogans in the area or from organised marches by anti-drugs protesters.

Interviewer: Do you think there are many drugs in this area?

Yeah, that is why they set up this meeting thing on every Tuesday night and they go on a march and march on people's houses. And they shout 'Pushers, Pushers, Pushers, Out, Out, Out.'

(No. 75, girl, 12 years) 
When asked if they actually knew anybody taking drugs, the majority of children reported that they did not. Of the sizeable minority who claimed that they did know drug-users, their proximity to these individuals was often rather distant, and the usual reference was to people or families known in the neighbourhood to be associated, with drugs.

I know one or maybe two. I don't know if he is a druggie or not. I know one of them. I was told he done drugs and he is trying to get off them. And [name a person] have you ever heard of him? He goes mad up in the shop, one day he had a helmet and he went mad

(No. 47, boy, 11 years)

Interviewer: Ok, do you know anyone in your area taking drugs?

Eh, I think there is cos everyone is talking about it... he goes and robs cars and all, just a door away from me.

(No. 54, boy, 10 years)

Three children referred to the deaths of young people they knew from drug abuse, in one case a neighbour, in the second a friend's girlfriend, and in the third the nephew other mother's friend. A small number of children revealed that close relatives had used drugs. One child reported that his uncle had died from inhaling substances, while another said that she believed that her mother used to smoke marijuana when she was younger. Another girl who reported that her uncle used drugs was quick to distinguish between 'soft' and 'hard' drug use:

Interviewer: Do you know anybody who ever tried any?

Yeah, me Uncle an all does. Me Uncle [name] and [names a person] yeah and [names a person] and [names a person] and all they just smoke hash like. You know all the big YMCA people they all smoke hash but not drugs like needles, cocaine, heroin and all that, none of that.

(No. 28, girl, 10 years)

What data in this subsection suggest is that by the various means described above, a considerable proportion of children had some form of contact with a drugs subculture that was more tangible than modes of contact such as mass-media coverage of drugs. However, as far as direct-personal knowledge of drug users was concerned, the vast majority of participants were not acquainted with drug users, and those who were generally indicated some social distance from such individuals.

\section{Children's direct experiences with drugs}

Given the environment in which the children lived, information was sought about whether or not they had ever experimented with or been offered drugs. Three children, all male, reported having tried cannabis, and one of these had also engaged in solvent sniffing. In two of the accounts of these three, the effects of cannabis were played down.

Hash doesn't really do that much to you.

Interviewer: Did you ever try it?

Yeah, once. 
Interviewer: And what was it like?

It was like smoking a normal [inaudible] just a bit stronger.

(No. 21, boy, 12 years)

Interviewer: Do you know anybody who takes drugs?

I smoke hash, and I know loads of people who do that.

Interviewer: You smoked hash. How does that feel?

It's like you take a drag off it but it does nothing to you though.

(No. 6, boy, 13 years)

The two examples above are classic representations of the 'techniques of neutrasation' referred to above. Participant number 21 states that hash does not 'do that much to you', and attempts to verify this from his experience. Participant number 6 alludes to his knowledge of 'loads of people' smoking marijuana (peer influence) as well as the inertness of the substance in his experience.

Further evidence that the children who reported having tried cannabis used such neutralisation techniques is found in their response to a question about whether or not they had been offered drugs. Two of the three boys (numbers 4 and 6) who had tried marijuana in this study claimed that they had never been offered drugs. Shiner and Newburn ${ }^{10}$ identify as examples of neutralisation techniques assertions by drug users that certain drugs are 'not really drugs' ( $p$ 524). This was the case even when the question arose in the context of a discussion on drugs during the interviews. Participant 6 also revealed that in addition to smoking cannabis, he had also practised solvent sniffing, but stopped when he learnt that his uncle had died from this form of abuse. That cannabis is seen as a 'soft' and thus not a 'real' drug is borne out in this extract from participant 6 (who had already imparted that he smoked hash):

Interviewer: Do you enjoy taking drugs?

I never really take drugs, I only did that with the haze bottles [aerosols]...

(No. 6, boy, 13 years)

It may also be the case that these young people frame the notion of being 'offered' drugs as something that happens when a stranger offers drugs rather than when the invitation to use drugs is made by someone in their social circle.

Apart from the above three cases, just one child reported that he had been approached in a public place. A small number of others revealed that a friend, acquaintance or close family member had been approached.

Interviewer: Were you ever offered any drugs?

No, my friend was ... she was kind of offered about it but she didn't tell her mam about it cos her mam would, she 'd flip and she wouldn't let her go anywhere.

(No. 18, girl, 12 years)

Interviewer: And have you ever been offered any?

No. There's a little young one in the flats, she only ten... Some junkie asked her had she any drugs. And then she said 'No', then she goes 'you're not to tell that you seen him asking me or I'll get battered'.

(No. 1, girl, 12 years) 
These accounts are revealing in so far as the children involved appear to be afraid to discuss drugdealing encounters with adults. This closes off the possibility of the children developing refusing skills which some adults might be able to teach, or some preparation for future encounters of a similar nature.

The enquiry by the interviewer about the child having possibly been offered drugs was sometimes met with hilarity, demonstrating the distance the child saw between himself or herself and drug-dealers.

Interviewer: Has anyone offered you drugs?

No. [child laughs at the suggestion]

(No. 53, girl, 12 years)

A common response to the line of questioning regarding experimenting with drugs was a clear indication of the child's disapproval of drug use.

Interviewer: Have you ever tried it?

No way!

Interviewer: And what about drugs? Have you ever...?

(No. 43, boy, 12 years)

Noooo!

Interviewer: Would you ever be tempted to try them?

(No. 28, girl, 10 years)

No. No, not drugs.

(No. 68, girl, 12 years)

As the above examples indicate, the strong emphasis on not having sampled drugs suggests that there was no doubt in these children's minds about revoking drugs.

\section{Knowledge and understanding of the effects of drugs}

Participants were questioned about their knowledge and understanding of the effects of drugs, and a variety of responses resulted. While a small proportion of children reported that they did not know the effects of drugs, the majority indicated an awareness of at least some of the negative outcomes of drug-use. It should be noted that not knowing the effects of drugs did not necessarily result in a child appearing more vulnerable to experimentation, as the following example suggests.

Interviewer: And what kind of effects do they have on you?

Effects? Don't know really. Just wouldn't go near them.

(No. 55, girl, 11 years)

Both the health and wider social effects of drug-use were noted in children's accounts. In most cases, death as a consequence of drug-use was most commonly referred to. Where effects other than or in addition to death were mentioned, they were sometimes referred to in very general terms.

Interviewer: And what kind of effects do you think they have on you?

Give you AIDS.

Interviewer: Give you AIDS? How do you get AIDS?

From the drugs. 
Interviewer: From the drugs, yeah?

I don't know how they give you AIDS but they give you AIDS anyway.

Interviewer: Do you know the effects of drugs?

(No. 40, girl, 11 years)

What do you mean?

Interviewer: What do drugs do to you?

Puts you in a bad state and all.

(No. 54, boy, 10 years)

Some children were more specific about the effects on one's mental and physical state that drugs can have.

Interviewer: Do you know what happens when you take drugs?

I know what happens when you take speed cos me sister did a project on it, you get all dizzy and hyper and all and you don't even know what is going on, you just sway all over the place, even if you got a glass bottle across the head you wouldn't know.

Interviewer: Really.

Yeah I was reading about it and like if someone smashed a glass bottle over your head you would be aaaahhh, but you wouldn't even say that hurts cos you wouldn't feel it, you are just dancing around getting hyper and all. Your head do be spinning.

Interviewer: What do you know about drugs?

(No. 38, girl, 12 years)

Well my Dad when he was in the Neighbourhood Network brought home a load of sheets, and I read through some of them, and like they make you go mad, and paranoid and, like, you conk out in places, and get sick and all.

(No. 68, girl, 12 years)

A small number of children noted the possibility of addiction to drugs.

Go mad and all and have an urge to get more drugs.

... you could take one, then two, and you might not be able to stop.

(No. 47, boy, 11 years)

(No. 67, girl, 11 years)

In terms of the wider social effects of drugs (which were mentioned to a lesser extent than physical health consequences), a variety of outcomes were noted. These included ruining one's life, losing family and friends, the financial costs of buying drugs, giving you a bad reputation, getting arrested, and even being petrol-bombed.

\section{DISCUSSION}

The general pattern emerging from the foregoing data is one of young people living in social environments where a drug subculture exists, yet at their present stage at least, the vast majority of children remained outside of that subculture, with most framing drug-taking practices in a negative way. This finding supports Shiner and Newburn's contention ${ }^{10}$ that the construction of drug taking by young people is generally consistent with established views on the issue, and is at variance with any notion that young people view drug taking as acceptable or 'normal'. Like those 
in Shiner and Newburn's sample, the small number of participants in this study who had used cannabis attempted to justify this by using neutralisation strategies; these served to counteract potential criticism of taking the drug by framing the substance and its use in benign terms (for example, 'it does nothing to you'). However, it should be noted that these children did demonstrate an acceptance of cannabis use, albeit within the restrictions they themselves defined.

An important point and strong note of caution is that while many child expressed unprompted disapproval of drug-use, this was not a feature of all the children's accounts. In addition to the three boys who had smoked cannabis, there were many accounts where no particular value judgement was offered (this is an aspect of methodological difficulties in interviewing children). While the dominant discourse on drug-taking to which participants were exposed was at variance with illegal drug-use, time will tell whether challenges to this discourse, or apathy towards it arising from adverse life circumstances, will mediate young people's earlier perspectives and shift some towards experimentation with drugs. Existing studies on drugs and young people in Ireland suggest that as the children get older this is indeed likely to occur.

\section{Acknowledgements}

The authors would like to thank the European Commission unit DG5 for funding this project.

\section{References}

1 ISDD. Drug Misuse in Britain 1994. London: Institute for the Study of Drug Dependence, 1994.

2 Mid-Western Health Board. Teenage Smoking, Drug and Alcohol use in the Midwest Limerick: Department of Public Health, Mid-Western Health Board, 1998.

3 Corrigan D. Facts About Drug Abuse in Ireland. Dublin: Health Promotion Unit, 1994.

4 National Consultative Committee on Health Promotion. Youth as a Resource: Promoting the Health of Young People at Risk. Dublin: Department of Health and Children, 1999.

5 Swedish Council for Information on Alcohol and Other Drugs. The 1995 European School Survey Project on Alcohol and Other Drugs. Swedish Council for Information on Alcohol and Other Drugs, 1997.

6 National Youth Council of Ireland. Get Your Facts Right. Dublin: National Youth Council of Ireland, 1998.

7 Coffield F, Gotten L. Drugs and Young People. London: Institute for Public Policy Research, 1994.

8 Measham F, Newcombe R, Parker H. The normalization of recreational drug use among young people in North-West England. British Journal of Sociology 1994: 45(2): 287-312.

9 Parker H, Measham F, Aldridge J. Drugs Futures: Changing Patterns of Drug Use amongst English Youth. London: Institute for the Study of Drug Dependence, 1995.

10 Shiner M, Newburn T. Definitely, maybe not? The normalisation of recreational drug use amongst young people. Sociology 1997: 31(3): 511-29.

11 Coggans N, McKellar S. Peer pressure: a convenient explanation. Druglink: The Journal on Drug Misuse in Britain 1994: 9: 16-18.

12 Sykes G, Matza D. Techniques of neutralization. American Sociological Review 1957: 22(6): 664-70.

13 Eden C. Fifty-seven ways to try to get data from 10 year old children. Paper presented at the European Conference on Educational Research, University of Bath, 14-17 September 1995. 


\section{REVIEWS}

Settings for Health Promotion: Linking Theory and Practice. BD Poland, LW Green, I Rootman (eds.). London: Sage, 2000.

The reader in search of an indigestible text-lack will be disappointed by Settings for Health Promotion: Linking Theory and Practice: With a summary of current thinking on what works' in health promotion, identification of gaps in knowledge and a historical review, the North American editors have combined theory and practice seamlessly. Anyone working in health care will recognise this as a major achievement.

The introduction defines health promotion, and reviews the settings approach from an ecological and critical social science perspective. Individual chapters cover: home and families; school; the workplace; the healthcare institution; clinical practice; community and state. There is at lest one commentary to each chapter, which adds a different perspective, critiques the approach taken and generally ensures that the complexities of the issues are explored.

I was most influenced by the chapters on the family and the state. The former brings insights from sociology and family therapy to a wider audience, with discussion of the family as a dynamic context for health, and exploration of alternative strategies for health promotion. 'The state as a setting' is written from a Canadian perspective, but the British reader will identify with most of the issues - the need for cross-departmental working in government, for example. This section is particularly well structured with historical reviews of policy feedback and parallels between environmental protection and health. If I had to select the most disappointing chapter, it would be 'health promotion in a clinical practice'. This is a balanced and comprehensive essay focused on the role of the primary care physician, but the subject is too complex to be condensed satisfactorily into 16 pages.

One of the strengths of this book is the contribution of different experts to each chapter. They combine to give the work a broad perspective and authoritative tone, though interpretation of the evidence is sometimes optimistic. Writing styles also vary, and some are definitely more readable than others. Many of the commentaries provide excellent summaries of the preceding chapter, and on a couple of occasions, I was left wishing that this author had been able to make a greater contribution. But these are minor criticisms of what is overall a substantial contribution to the literature.

This book will be well received by students and researchers, but it will be a shame if it does not find an audience among practising health promotion specialists. The tone is academic but the content will be useful to the practitioner with limited interest in theory who has to justify their work in an increasingly evidence-based health system. In an ideal world, this book would be read by managers and policy makers in settings beyond health care. I would recommend it to specialists and commissioners of health promotion and anyone training in public health.

\section{Barbara Hanratty \\ Department of Public Health University of Liverpool}

\section{Researching Health Promotion. Edited by Jonathan Watson and Stephen Platt. London: Routledge, 2000.}

Researching Health Promotion is about the challenges which face health promotion research in the 21st century. Jonathan Watson and Stephen Platt whet the reader's appetite by addressing a number of important issues facing health promotion research in their opening chapter 'Connecting policy and practice', such as the need for the research community (regardless of their methodological paradigms) to work together and 'to make the fullest use of existing non-experimental designs and devise new strategies which capture evolution and change in process'.

The rest of the book is then divided into three sections. The first chapter, 'Fresh 